\title{
Fatal Insomnia; the elusive Prion disease
}

\author{
SUMMARY
}

A previously well 54 year old lady (PT) presented with a short history of diplopia, cognitive decline, hallucinations and hypersomnolence. PT had progressive deterioration in short-term memory, ocular convergence spasm, tremor, myoclonus, gait apraxia, central pyrexia, dream enactment and seizures. Results of investigations were normal including MRI brain, EEG, CSF (including CSF prion protein markers) and brain biopsy. PT died from pneumonia and pulmonary embolus. Brain post mortem analysis revealed neuropathological changes in keeping with Fatal Familial Insomnia (FFI); the diagnosis was confirmed on genetic testing. $\mathrm{FFI}$ is caused by an autosomal dominant and highly penetrant pathogenic Prion Protein gene PRNP. Although usually familial, Fatal Insomnia (FI) also occurs in a rare sporadic form $(\mathrm{sFI})$. $\mathrm{FI}$ is a rare human prion disease with prominent sleep disturbance, autonomic, motor and cognitive and behavioural involvement. Patient management is with best supportive care and early suspected diagnosis allows for timely palliation.

\section{BACKGROUND}

'Fatal Insomnia; the elusive Prion disease' illustrates a difficult case of a patient with the presenting features and natural history of a prion disorder, in the face of negative familiar investigations and newer highly sensitive and specific CSF methods. We aim to highlight that difficult and rare neurological cases may present acutely to hospital, sometimes via other specialties. The case is likely to resonate with BMJ readers as our initial 'gut' diagnosis proved correct despite off-putting investigation results. We discuss the epidemiology, clinical features, investigations, neuropathology, neurogenetics and supportive management of patients with Fatal Insomnia.

\section{CASE PRESENTATION}

A previously well 54 year old lady (PT) developed new onset diplopia followed by hearing impairment and 'seashell' tinnitus over several weeks. Four months following symptom onset, ophthalmic assessment found decompensated esophoria and ocular convergence spasm. Her family told the Ophthalmologist that she had been struggling with recent memory: her Acute Mental Test Score was reduced at 7/10. MRI brain with MR Angiography showed non-specific deep white matter changes in keeping with known vascular risk factors.

A range of screening tests gave negative results (Table 1). PT's tinnitus improved with the provision of hearing aids. However, two months later she was admitted to hospital with rapid cognitive decline, such that she had forgotten the names of her relatives. The family reported auditory and visual hallucinations, involuntary movements, daytime somnolence and low mood. 
PT suffered from borderline Diabetes Mellitus and hypertension for which she took Amlodipine. She had undergone gastric banding or a balloon procedure in Spain many years previously, was an ex-smoker and did not drink alcohol. She was one of thirteen children, was separated from her partner and had five healthy children by two different partners. There was no neurological or otherwise relevant family history.

On examination, PT had flattened affect, short term memory impairment, ocular convergence spasm, tremor, myoclonus and severe gait apraxia. At times she appeared to have hypnopompic hallucinations. There were no pyramidal, extrapyramidal or cerebellar signs. Addenbrooke's cognitive assessment III (ACE) revealed a score of 34/100, deficient in all domains, particularly memory and verbal fluency. Her clinical state deteriorated rapidly; she had multiple fevers of central origin and developed clinically apparent sleep apnea (although this could not be confirmed formally as she removed pulse oximetry leads). PT had several probable seizures with eye rolling, unresponsiveness, posturing of the right arm and limb twitching. Her ACE score fell to 20/100 one month after admission to hospital.

The results of in-hospital radiographic and specialist investigations are summarized in Table 2.

\section{INVESTIGATIONS If relevant}

Table 1: Summary of results of blood tests and CSF examination performed during hospital admission.

\begin{tabular}{|c|c|c|c|}
\hline \multicolumn{4}{|l|}{ Serum Results } \\
\hline WCC & 12.5 & HbA1C & Normal \\
\hline Platelets & 454 & Plasma viscosity & Normal \\
\hline CRP & 11 & B12 \& Folate & Normal \\
\hline Urea \& Electrolytes & Normal & TSH & Normal \\
\hline Liver function Tests & Normal & $\mathrm{T} 4$ & 23.4 \\
\hline Calcium \& Phosphate & Normal & Vasculitic Screen & Negative \\
\hline Magnesium & Normal & ANA Speckled & Titre 1:80 \\
\hline \multicolumn{4}{|c|}{ Negative Antibody Screen } \\
\hline \multicolumn{2}{|c|}{$\begin{array}{l}\text { Voltage-gated Potassium Channel Antibodies } \\
\text { NMDA receptor Antibodies } \\
\text { Anti-neuronal Antibodies } \\
\text { IgLON5 Antibodies } \\
\text { Anti-ganglioside (G01b) Antibodies }\end{array}$} & \multicolumn{2}{|c|}{$\begin{array}{l}\text { Glutamic Acid Decarboxylase (GAD) Antibodies } \\
\text { Acetylcholine Receptor Antibodies } \\
\text { TSH Receptor Antibodies } \\
\text { Thyroid Peroxidase Antibodies }\end{array}$} \\
\hline \multicolumn{4}{|c|}{ Negative Microbiology \& Virology Tests } \\
\hline \multicolumn{4}{|l|}{$\begin{array}{l}\text { HIV Screen } \\
\text { VDRL Test } \\
\text { Legionella } \\
\text { Pneumococcal Disease } \\
\text { Mycoplasma } \\
\text { Coxiella Burnetti } \\
\text { Viral Hepatitis Screen }\end{array}$} \\
\hline \multicolumn{4}{|l|}{ CSF Examination } \\
\hline $\begin{array}{l}\text { Opening pressure } \\
\text { Constituents- WCC, prot } \\
\text { Microbiology, Culture a } \\
\text { Viral PCR } \\
\text { Oligoclonal Bands } \\
\text { S100 \& 14-3-3 proteins } \\
\text { RT QuiC protein }\end{array}$ & $\begin{array}{l}\text { nd glucose } \\
\text { g }\end{array}$ & $\begin{array}{l}\text { Normal } \\
\text { Normal } \\
\text { Negative } \\
\text { Negative } \\
\text { Negative } \\
\text { Negative } \\
\text { Negative }\end{array}$ & \\
\hline
\end{tabular}


Table 2: Summary of radiographic and specialist investigations performed during hospital admission.

\begin{tabular}{|ll|}
\hline Imaging & \\
\hline MRI Brain with Contrast \& MR Angiogram & $\begin{array}{l}\text { Non-specific deep white matter vascular } \\
\text { changes with a normal Circle of Willis. No } \\
\text { evidence of restricted diffusion }\end{array}$ \\
\hline Chest X-ray & Normal \\
\hline Specialist Investigations & $\begin{array}{l}\text { Oesophageal thickening, but no evidence of } \\
\text { overt malignancy }\end{array}$ \\
\hline Electroencephalography & $\begin{array}{l}\text { Intermittent sharp waves in the left } \\
\text { centroparietal region but no periodic sharp } \\
\text { wave complexes seen }\end{array}$ \\
\hline Repeat Electroencephalography & $\begin{array}{l}\text { Excess bilateral slow waves but no abnormality } \\
\text { correlated with myoclonus }\end{array}$ \\
\hline Fluorescein Retinal Angiogram & No evidence of retinal vasculitis \\
\hline Frontal Brain \& Meninges Biopsy & $\begin{array}{l}\text { Normal Specimen. No evidence of prion protein, } \\
\text { lymphoma or leptomeningeal vasculitis }\end{array}$ \\
\hline Oesophageal Duodenoscopy & $\begin{array}{l}\text { Atypical oesophagitis, histology revealed a } \\
\text { gastro-oesophageal ulcer }\end{array}$ \\
\hline
\end{tabular}

\section{DIFFERENTIAL DIAGNOSIS}

We initially considered differential diagnoses of Creutzfeldt-Jakob disease, autoimmune encephalitis, intravascular lymphoma and dementia with Lewy Bodies (DLB). Serological tests of nutritional status were not performed, but in retrospect measures of Vitamin B1 for Wernicke's Encephalopathy and Vitamin E for ataxia, would have been appropriate additions to our test battery, in view of the possibility of malnutrition linked to past bariatric surgery.

Given a positive DAT scan result (Figure 1) in the face of otherwise negative investigation including brain biopsy, atypical DLB was our working diagnosis.

Subsequent post-mortem brain examination showed marked gliosis of the thalamic and inferior olivary nuclei (Figure 2, panel A and B). However, immunohistochemistry showed no evidence of any spongiform change or convincing prion protein (PrP) accumulation in the brain (Figure 2, panel C). Subsequent paraffin embedded tissue blot (PET blot) analysis undertaken by the National CJD Research \& Surveillance Unit (NCJDRSU) in Edinburgh showed accumulation of the misfolded form of the prion protein ( $\mathrm{PrPS}^{\mathrm{Sc}}$ ) in the medial temporal lobe (Figure 2, panel D). Frontal Cortex (FC) and Cerebral Cortex (CC) samples were selected for biochemical analysis. The tissue samples were homogenised and precipitated with Sodium phosphotungstic acid (NaPTA) followed by proteolytic digestion with Proteinase $\mathrm{K}(\mathrm{PK})$ and high-sensitivity Western blotting.[1] Western blot analysis showed detectable levels of partially protease-resistant fragments in brain samples (FC and CC) using the monoclonal antibody 3F4, typed as "type 2B" (Figure 2, panel E). Genetic analysis revealed the D178N (aspartic acid to arginine) pathogenic variant in the PRNP gene [c.532G>A p.(Asp178Asn)], in combination with methionine homozygosity at codon 129 (MM) of the same gene in keeping with a diagnosis of Fatal Familial Insomnia (FFI). 


\section{TREATMENT}

Treatment with Rivastigmine for atypical DLB was unhelpful. No immunotherapy was tried on the basis that the aetiology was unknown but was presumed to be a neurodegenerative process.

Family members were subsequently offered counselling by our clinical genetics team.

\section{OUTCOME AND FOLLOW-UP}

PT was discharged to a nursing home but readmitted forty-eight hours later with hospital-acquired pneumonia and pulmonary embolus. She died two days later, six to seven months after first symptom onset.

\section{DISCUSSION}

Fatal Insomnia $(\mathrm{FI})$ is a rare human prion disease, which occurs in both sporadic (sFI) and familial forms (FFI). It typically presents with prominent sleep disturbance, and is usually inherited.[2] As a group, the transmissible spongiform encephalopathies -prionopathies or prion diseases - occur in sporadic, inherited and acquired forms. All involve the accumulation of an aggregated and partially protease-resistant form ( $\mathrm{PrP}^{\mathrm{Sc}}$ ) of the prion protein (PrP) with the capacity to drive the further conversion of normal $\operatorname{PrP}$ molecules $\left(\mathrm{PrP}^{\mathrm{c}}\right)$ into the misfolded, protease resistant and disease associated isoform.[2] Sporadic Creutzfeldt-Jakob disease (sCJD) is the most common human prion disease, with a world-wide incidence of around 1-2 cases per million population/year.

FI is much rarer: only 70 known affected kindreds and 25 typical cases of sFI have been reported world-wide.[2] Age of onset in FFI varies between 36-72 years affecting males and females equally. sFI has been reported in a handful of cases with similar clinical and neuropathological features to the familial phenotype.[3] The clinical features of FI involve sleep, autonomic, motor, behavioural and cognitive disturbance. However, although titled 'Fatal Insomnia', insomnia is not a defining feature of the disease. Involvement of the thalamus, hypothalamus and higher brainstem can affect sleep in a variety of ways. Insomnia is the most frequently observed sleep disturbance, but REM sleep behaviour disorder and dream enactment may also be seen. Early clinical manifestations include altered vigilance, fluctuating diplopia, disrupted circadian rhythm, apathy and executive dysfunction. Nocturnal sleep disturbance can lead to daytime somnolence. Autonomic features may then ensue with hypertension, evening pyrexia, perspiration, lacrimation, salivation and impotence. Gait apraxia, ataxia, myoclonus and other motor signs (Table 3) may emerge as the disease progresses. Occasional convulsive seizures have been reported.[3] Patients may die as a result of secondary pneumonia.[3]

Other forms of human Prion disease, atypical Parkinsonism, Dementia with Lewy Body disease, Autoimmune Encephalitis and Intravascular Lymphoma should all be considered when investigating for FI.[1]

As this case illustrates, standard investigations in life may be normal. The following investigations may assist in the suspected diagnosis of $\mathrm{FI}$; MRI of the brain may show non-specific changes of cortical, cerebral and cerebellar atrophy.[2,3] Cortical ribboning seen in SCJD and diffusion restriction changes on diffusion-weighted MRI brain, are not seen in FI.[2] Periodic complexes on an 
EEG of the kind seen in CJD, are not typically present but may develop in patients with a long duration of illness. Abnormality of Cerebrospinal fluid (CSF) 14-3-3 protein occurs in only 50\% patients with FI.[2] CSF RT Quic is positive in $83 \%$ of $\mathrm{FFI}$ cases but only in $50 \%$ of sFI patients. PET Fluorodeoxyglucose has shown hypometabolism in the thalamus, basal ganglia and limbic system in some cases.[2,3]

Polysomnography may show disruption of the sleep wake cycle,[2] with sleep state dissociation (loss of the normal boundaries between non-REM sleep, REM sleep and wakefulness). Total duration of sleep is often reduced and slow wave sleep may be lost entirely. Hypercortisolaemia and low melatonin levels have been reported.[3,4]

Fatal Insomnia is caused by the highly penetrant, autosomal dominant, pathogenic Prion Protein gene (PRNP) variant c.532G>A p.(Asp178Asn) on chromosome 20, previously called the D178N mutation.[5] The codon 129 variant on the same allele modifies the phenotype expressed at codon 178; with p.Met129 the phenotype is usually FI whereas with p.Val129 it is usually typical CJD.[5]

Neuropathological assessment at post mortem remains the definitive means of confirming a diagnosis of FI. Neuropathological changes in FI include prominent thalamic,[4] and inferior olivary neuronal loss and astrogliosis.[2] Cortical and subcortical gliosis may be seen to a milder degree as well as spongiform degeneration later in the course of disease, with more extensive changes observed as the disease progresses. PET blot analysis may be useful in the detection $\operatorname{PrP}^{\mathrm{Sc}}$ when standard immunohistochemical methods fail to detect evidence of the prion protein.[6]

The management of $\mathrm{Fl}$ is currently supportive, with genetic counselling for at risk family members.

Table 3: Phenotypic Features of Fatal Insomnia

\begin{tabular}{|ll|}
\hline Sleep \& behavioural \\
\hline - Insomnia \\
- Altered vigilance \\
- Progressive dementia \\
\hline Motor \\
\hline - Tremor & - Dysphagia \\
- Myoclonus & - Diplopia \\
- Ataxia & - Pyramidal signs \\
\hline - Dysarthria & - Positive Babinski reflex \\
\hline - Hysautonomia & - Gait apraxia \\
\hline - Persening Pyrexia & \\
\hline
\end{tabular}

\section{Conclusion}

We initially suspected a diagnosis of a prion disease in this case of rapidly progressive dementia with prominent somnolence, gait apraxia and myoclonus. We were discouraged from the diagnosis by negative investigations including CSF examination and brain biopsy. Formal polysomnography might have suggested the diagnosis, but was difficult to perform in this agitated patient. A neuropathological post-mortem of PT's brain eventually provided the crucial clue to the correct diagnosis, of $\mathrm{FFI}$, with confirmation by further specialised neuropathological and genetic assessment by the NCJDRSU. We have since offered genetic counselling to at risk family 
members. For those wishing to learn more of the human dimension of FFI, a moving documentary, Dying to Sleep, is available at https://www.youtube.com/watch?v=AxjNay TRRg

\section{LEARNING POINTS/TAKE HOME MESSAGES 3-5 bullet points}

- Fatal Insomnia is a rare prion disease with prominent sleep disturbance, cognitive, autonomic, motor and behavioural involvement.

- Fatal Familial insomnia is highly penetrant and arises from the Prion Protein gene (PRNP) variant c.532G>A p.(Asp178Asn) on chromosome 20, previously called the D178N mutation.

- Sporadic Fatal Insomnia has similar clinical and neuropathological features to Fatal Familial Insomnia.[7]

- Standard screening tests for investigating human prion disease such as MRI brain, EEG and CSF can be normal. Polysomnography and FDG PET may support a diagnosis of FI but genetic and neuropathological assessment remains key to confirming the diagnosis.

- Management is best supportive care but early suspicion allows timely planning for the terminal phase of life. Family members should be supported and offered genetic counselling.

\section{REFERENCES}

1. A Peden, L McCardle, M W Head, S Love, H J T Ward, S N Cousens, D M Keeling, C M Millar, F G H Hill, J W Ironside. Variant CJD infection in the spleen of a neurologically asymptomatic UK adult patient with haemophilia. Haemophilia. 2010 Mar;16(2):296-304. doi: 10.1111/j.1365-2516.2009.02181.x. Epub 2010 Jan 12.

2. Handbook of clinical neurology. Human Prion Diseases. Cracco L, Appleby B, Gambetti P. Volume 153 2018. p271-299

3. Familial and Sporadic Fatal Insomnia. P Montaga, P Gambetti et al. Review. THE LANCET Neurology. Volume 2 March 2003 p167-176

4. Fatal Familial Insomnia and dysautonomia with selective degeneration of thalamic nuclei. New England Journal of Medicine 1986. 315: 997-1003.

5. Review: Prion Disease Genetics. European Journal of Human Genetics. Simon Mead. 2006 (14) 273-281.

6. Technical Advance. The Paraffin-Embeded Tissue Blot detects PrPSc early in the incubation time for Prion Diseases. Schulz-Schaeffer W.J et al. American Journal of Pathology. January 2000. Vol 156 (1)

7. A subtype of sporadic prion disease mimicking fatal familial insomnia. Neurology. 1999 Jun 10;52(9):1757-63. Parchi P1, Capellari S, Chin S, Schwarz HB, Schecter NP, Butts JD, Hudkins P, Burns DK, Powers JM, Gambetti P. 
Figure 1: DAT scan showing bilateral abnormal uptake of tracer in the basal ganglia.

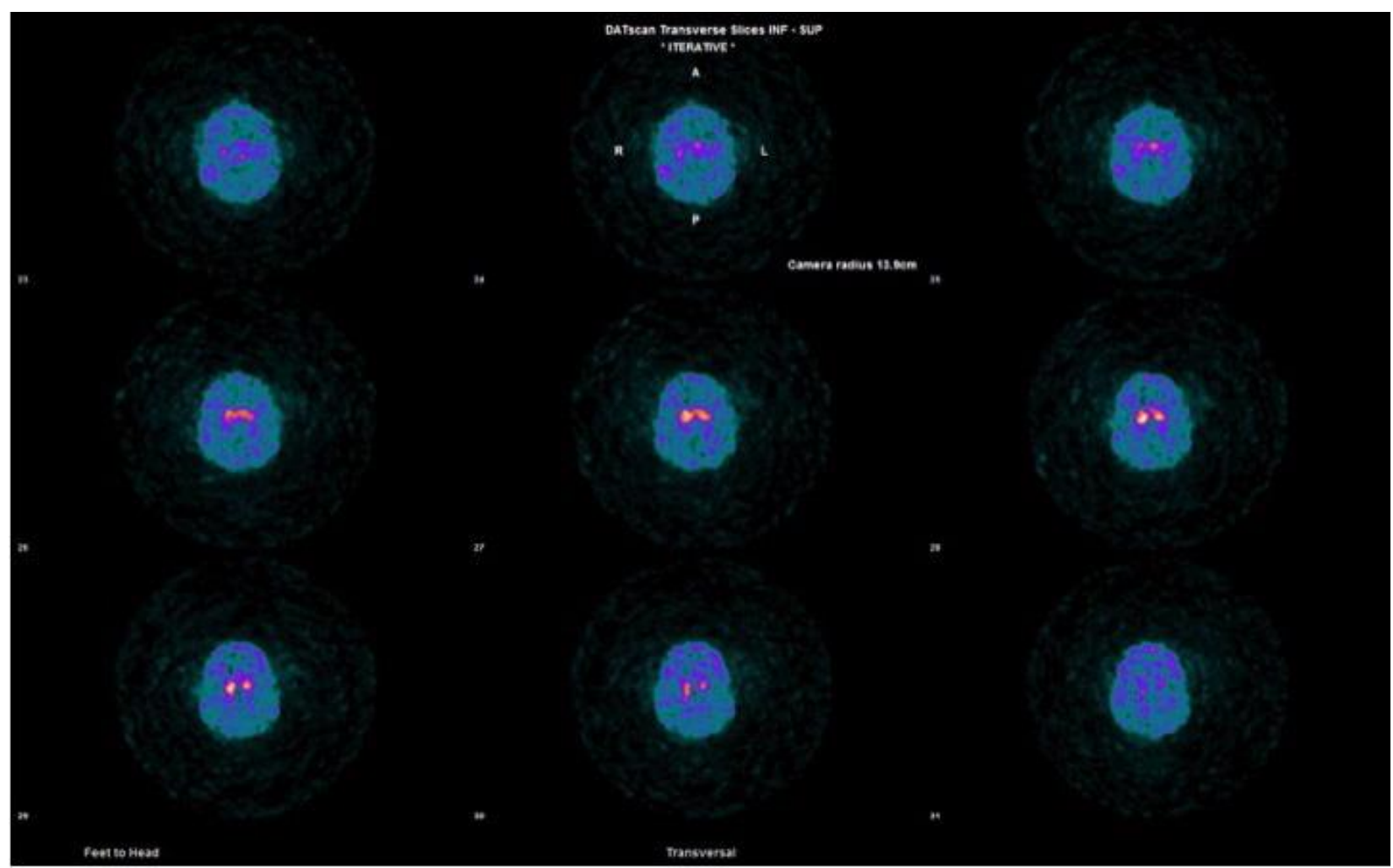

Figure 2: Neuropathological analysis, undertaken at the National Creutzfeldt-Jakob Disease Research and Surveillance Unit (NCJDRSU). Routine histological assessment using a haematoxylin and eosin (H\&E) stain showed striking thalamic gliosis (a; x10 magnification) confirmed by immunohistochemical assessment of glial fibrillary acidic protein (GFAP) expression (b; x10 magnification). Immunohistochemical assessment of abnormal prion protein expression was assessed using a number of antibodies but was mostly negative (c; $12 \mathrm{~F} 10 \times 10$ magnification) and only focal weak expression. However, the paraffin-embedded tissue (PET) blot technique clearly demonstrated abnormal prion protein (d). Western blot analysis of PrPsc in Fatal Familial Insomnia, codon 129MM, type 2B (FFI), compared with sporadic CJD MM1 (sCJDMM1), type 1A; sporadic CJD MM2 (sCJDMM2), type 2A; and variant CJD MM (vCJD), type 2B. For the FFI case, PrPSc analysis of Frontal Cortex (FC) and Cerebral Cortex (CC) were considered. M, molecular marker (E). 

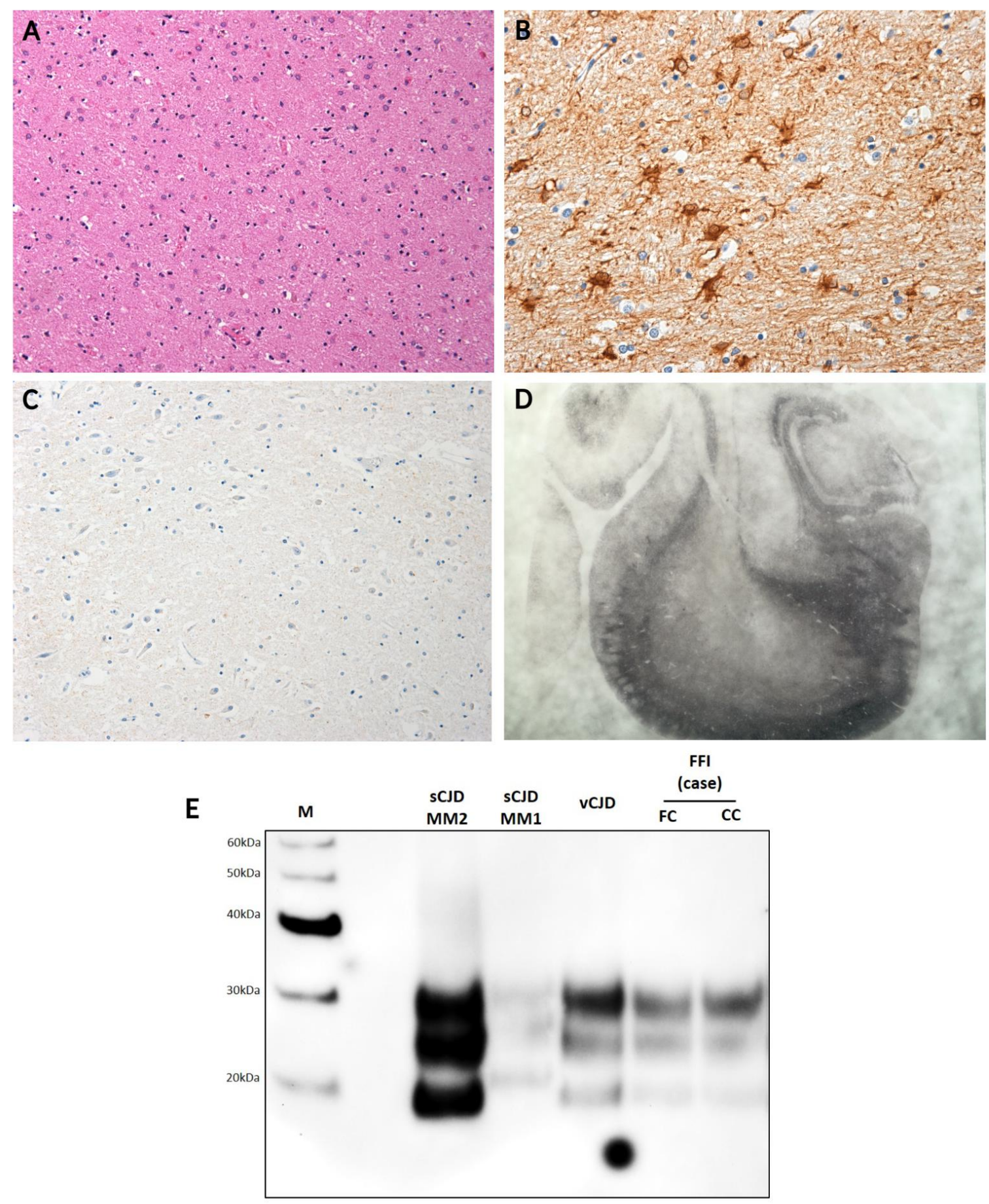

\section{INTELLECTUAL PROPERTY RIGHTS ASSIGNMENT OR LICENCE STATEMENT}

I, Dharmini Patel, the Author has the right to grant and does grant on behalf of all authors, an exclusive licence and/or a non-exclusive licence for contributions from authors who are: i) UK Crown employees; ii) where BMJ has agreed a CC-BY licence shall apply, and/or iii) in accordance with the relevant stated licence terms for US Federal Government Employees acting in the course of the their employment, on a worldwide basis to the BMJ Publishing Group Ltd ("BMJ") and its licensees, to permit this Work (as 
defined in the below licence), if accepted, to be published in BMJ Case Reports and any other BMJ products and to exploit all rights, as set out in our licence author licence.

Date: 05/05/2021

PLEASE SAVE YOUR TEMPLATE WITH THE FOLLOWING FORMAT:

Submitting author's last name and date of submission, e.g. Smith_November_2018.doc 